\title{
Comparison of Destructive and Nondestructive Sampling Techniques of Retail Chicken Carcasses for Enumeration of Hygiene Indicator Microorganisms
}

\author{
MARCUS VINÍCIUS COUTINHO COSSI, MICHELLE VIEIRA DE ALMEIDA, MARIANE REZENDE DIAS, \\ PAUlO SÉRGiO de ARRUdA PINTO, AND LUÍS AUGUSTO NERO*
}

Departamento de Veterinária, Universidade Federal de Viçosa, Campus Universitário, 36570-000, Viçosa, Minas Gerais, Brazil

MS 11-247: Received 17 May 2011/Accepted 9 September 2011

\begin{abstract}
The type of sampling technique used to obtain food samples is fundamental to the success of microbiological analysis. Destructive and nondestructive techniques, such as tissue excision and rinsing, respectively, are widely employed in obtaining samples from chicken carcasses. In this study, four sampling techniques used for chicken carcasses were compared to evaluate their performances in the enumeration of hygiene indicator microorganisms. Sixty fresh chicken carcasses were sampled by rinsing, tissue excision, superficial swabbing, and skin excision. All samples were submitted for enumeration of mesophilic aerobes, Enterobacteriaceae, coliforms, and Escherichia coli. The results were compared to determine the statistical significance of differences and correlation $(P<0.05)$. Tissue excision provided the highest microbial counts compared with the other procedures, with significant differences obtained only for coliforms and E. coli $(P<0.05)$. Significant correlations $(P<0.05)$ were observed for all the sampling techniques evaluated for most of the hygiene indicators. Despite presenting a higher recovery ability, tissue excision did not present significant differences for microorganism enumeration compared with other nondestructive techniques, such as rinsing, indicating its adequacy for microbiological analysis of chicken carcasses.
\end{abstract}

Systematic analysis of hygiene indicator microorganisms is a basic precept of various food quality control programs, such as hazard analysis and critical control points, which monitor hygienic conditions throughout the food chain (13). In particular, assays for specific groups of microorganisms might indicate the potential presence of pathogens, highlighting their importance in adequate contamination control and ensuring the safety of the final products $(3,8,20)$.

A critical factor affecting the accuracy of microbiological data from animal carcasses is selection of an appropriate sampling procedure $(18,22)$. Various techniques can be adopted by food industries and official inspection agencies and are usually classified as either destructive or nondestructive (3). For chicken carcasses, several sampling procedures have been evaluated $(3,4,7,10,11,13,21)$, and a destructive procedure (tissue excision) has been reported to be more accurate for defining microbiological contamination levels $(9,19)$. This procedure has been adopted by Brazilian inspection agencies for the analysis of chicken carcasses and avian products (2).

In contrast, food industries tend to adopt nondestructive procedures in order to maintain the integrity of the carcasses, thereby preserving its natural characteristics and

\footnotetext{
* Author for correspondence. Tel: + 55313899 1463; Fax: + 55313899 1457; E-mail: nero@ufv.br.
}

allowing for the commercial production of specific cuts. For instance, avian industries usually adopt the carcass rinsing sampling procedure to evaluate microbiological contamination during slaughtering and in the final products. This procedure has also been adopted by the U.S. Department of Agriculture, Food Safety and Inspection Services (USDA/ FSIS) (23) for detection of Salmonella spp. and Escherichia coli in chicken. Some studies have reported that nondestructive sampling is less effective at recovering specific microorganisms, possibly resulting in an underestimation of the real level of microbiological contamination during quality control and leading to potential safety risks $(10,11)$.

Several sampling procedures, including rinsing and superficial swabbing, have been developed to evaluate microbiological contamination in chicken carcasses (3). In general, inspection agencies consider destructive sampling procedures to be official, and these agencies do not accept microbiological results obtained by other sampling procedures. Because this official testing is performed on the end products, it is necessary to evaluate the possible differences among distinct sampling procedures in chicken carcasses available to consumers.

For a proper comparison between microbiological data obtained by distinct sampling techniques, it is necessary to establish correlations among them (3). Results from this direct comparison can be used as a reference when choosing which procedure is most suitable for microbiological 
monitoring of animal carcasses, by taking into consideration the product characteristics and the quality and safety goals of a particular industry or even an entire country (10). The aim of this study was to compare destructive (tissue excision and skin excision) and nondestructive (swab and rinsing) sampling methods used in poultry carcasses for the enumeration of hygiene-indicator microorganisms.

\section{MATERIALS AND METHODS}

Chicken carcasses and sampling procedures. A total of 60 refrigerated chicken carcasses available for retail sale were bought from commercial establishments in Viçosa and the surrounding area in Minas Gerais, Brazil. Each carcass was purchased in its original packaging and kept refrigerated $\left(4^{\circ} \mathrm{C}\right)$ until laboratory analysis (no more than $2 \mathrm{~h}$ after collection).

The tested sampling procedures were conducted according the recommendations by Capita et al. (3). Under aseptic conditions, each carcass was divided into equal halves along the section of the spinal column with a sterile knife. One half was used to obtain a nondestructive sample by rinsing, according to a method modified from the USDA/FSIS protocol (23). Each half-carcass was transferred to a sterile bag and weighed, and an equal volume of sterile buffered peptone water $(0.1 \%$; Oxoid Ltd., Basingstoke, England) was added. The half-carcass was then rinsed with rocking motion for $5 \mathrm{~min}$, while ensuring that all surface areas were covered by the rinsing solution. Then, the carcass was aseptically removed, and the liquid was drained into the bag.

The other half of the carcass was sampled by two destructive techniques (tissue excision and skin excision) and a nondestructive technique (superficial swabbing). Breast and dorsal portions of this half-carcass were divided into six defined areas of $25 \mathrm{~cm}^{2}$ (5 by $5 \mathrm{~cm}$ ) with sterile molds, which were used as references for obtaining samples by the procedures evaluated in this study. To obtain samples for each procedure, two areas were randomly selected from the half-carcass (Fig. 1).

Two of the selected areas were swabbed (swabbing technique, nondestructive) using sponges ( 7 by 4 by $4 \mathrm{~cm}$, without antimicrobial agents and obtained from local stores, previously sterilized and moistened with $5 \mathrm{ml}$ of $0.1 \%$ buffered peptone water [Oxoid]), which were then transferred to sterile bags. Then, $45 \mathrm{ml}$ of $0.1 \%$ buffered peptone water (Oxoid) was added to each bag, and the bags were homogenized in a stomacher.

For tissue excision (destructive), skin fragments and muscular tissue were removed from the selected areas of the half-carcass with a sterile scalpel and calipers, and these portions were

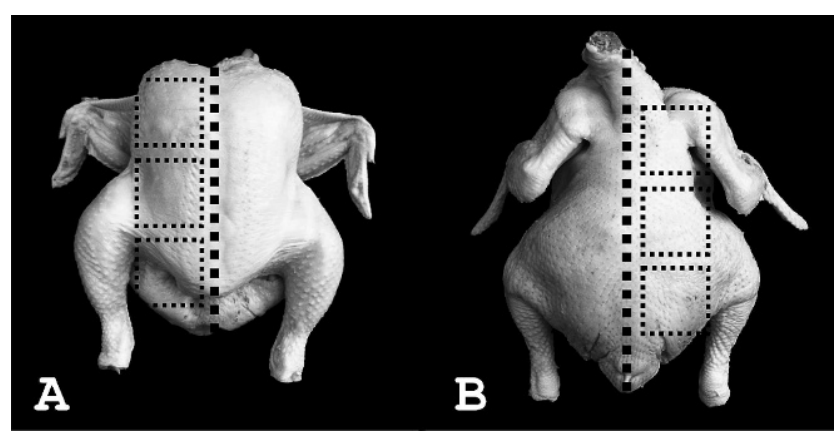

FIGURE 1. Front (A) and dorsal (B) view of a chicken carcass demonstrating the division in two halves (dotted line in the middle of carcass), one half being reserved for rinsing, and the definition of six areas (dotted line squares) to obtain the samples by tissue excision, skin excision, and skin swabbing. transferred to sterile bags with a total weight of $25 \mathrm{~g}$. Then, $225 \mathrm{ml}$ of $0.1 \%$ buffered peptone water (Oxoid) was added, and the mixture was homogenized in a stomacher.

For skin excision (destructive), skin portions were removed with a sterile scalpel and calipers from selected areas, transferred to sterile bags containing $50 \mathrm{ml}$ of $0.1 \%$ buffered peptone water (Oxoid), and homogenized with a stomacher.

The resulting solutions obtained by all sampling techniques were 10 -fold diluted with $0.1 \%$ buffered peptone water (Oxoid) and used for enumeration of hygiene indicator microorganisms. Only the resulting homogenate from tissue excision was considered as a 1:10 dilution.

Enumeration of hygiene indicator microorganisms. The dilutions obtained by the above four sampling procedures from each chicken carcass were plated on Petrifilm (3M Microbiology, St. Paul, MN) for enumeration of different groups of hygiene indicator microorganisms. Aerobic mesophiles were enumerated on Petrifilm aerobic count plates incubated at $35 \pm 1{ }^{\circ} \mathrm{C}$ for $48 \pm$ $3 \mathrm{~h}$. The resulting red colonies were counted. For the enumeration of Enterobacteriaceae, Petrifilm Enterobacteriaceae was used, incubated at $35 \pm 1{ }^{\circ} \mathrm{C}$ for $24 \pm 2 \mathrm{~h}$. The resulting yellow colonies that formed (with or without gas production) were counted. Coliforms and E. coli cells were enumerated using Petrifilm Escherichia coli plates incubated at $35 \pm 1{ }^{\circ} \mathrm{C}$ for $24 \pm 2 \mathrm{~h}$. Colonies with gas production were enumerated as coliforms, and blue colonies with gas production were enumerated as E. coli. All results were expressed in CFU per gram (for tissue excision) or milliliter (for the sample homogenate obtained by rinsing, skin swabbing, and skin excision) of the sample homogenate obtained by the distinct sampling techniques.

Data analysis. All the microorganism counts were converted to a $\log$ scale and were evaluated for normality and homogeneity. Values were compared by the Kruskal-Wallis $(P<0.05)$ method for evaluation of significant differences between the sampling techniques, with pairwise comparisons performed using a MannWhitney $\mathrm{U}$ test $(P<0.05)$. In addition, the counts obtained by each sampling technique were compared using a Spearman correlation $(P<0.05)$. All statistical analyses were performed using Statistica 7.0 (StatSoft Inc., Tulsa, OK) and XLSTAT 2009.1.02 (Addinsoft USA, New York, NY) software.

\section{RESULTS AND DISCUSSION}

In general, minor differences between the tested sampling procedures of chicken carcasses were observed (Table 1). Tissue excision was the procedure that was able to recover the highest counts of hygiene indicator microorganisms when compared to all other methods, as observed in other studies $(3,12)$.

Despite the small differences between the observed counts, the obtained data were analyzed to verify the significance of these differences (Table 1). Tissue excision was able to recover the highest counts of microorganisms but was statistically higher than all the other techniques for enumeration of coliforms and E. coli only. Interestingly, for mesophilic aerobes and Enterobacteriaceae, tissue excision was not statistically superior to rinsing, a nondestructive method. Similar to the results presented here, several studies have reported that tissue excision sampling yields the highest recovery of hygiene indicator microorganisms (12, 15, 17). 
TABLE 1. Statistical parameters of hygiene indicator microorganisms counts from 60 fresh chicken carcasses analyzed by distinct sampling procedures

\begin{tabular}{|c|c|c|c|c|c|c|}
\hline \multirow{2}{*}{$\begin{array}{l}\text { Hygiene indicator } \\
\text { microorganism group }\end{array}$} & \multirow[b]{2}{*}{ Sampling procedure } & \multicolumn{4}{|c|}{ Statistical parameters ${ }^{a}$} & \multirow[b]{2}{*}{ Statistical analysis ${ }^{b}$} \\
\hline & & Mean & Min & $\operatorname{Max}$ & $\operatorname{Median}\left(\mathrm{Q}_{1}-\mathrm{Q}_{3}\right)$ & \\
\hline \multirow[t]{4}{*}{ Mesophilic aerobes } & Rinsing & 5.3 & 3.0 & 6.7 & $5.3(5.0-6.1) \mathrm{ABC}$ & $\mathrm{H}=8.1$ \\
\hline & Tissue excision & 5.6 & 4.0 & 7.2 & $5.4(5.0-6.2) \mathrm{A}$ & $P=0.04$ \\
\hline & Skin excision & 5.1 & 3.3 & 6.6 & $5.2(4.5-5.9)$ в & \\
\hline & Skin swab & 5.1 & 3.0 & 6.6 & $5.2(4.5-6.0)$ вС & \\
\hline \multirow[t]{4}{*}{ Enterobacteriaceae } & Rinsing & 3.9 & 2.0 & 5.5 & $3.9(3.5-4.5) \mathrm{ABC}$ & $\mathrm{H}=10.0$ \\
\hline & Tissue excision & 4.2 & 2.0 & 6.3 & $4.2(3.6-4.6) \mathrm{A}$ & $P=0.02$ \\
\hline & Skin excision & 3.8 & 2.0 & 5.5 & $3.8(3.3-4.2)$ в & \\
\hline & Skin swab & 3.8 & 2.0 & 5.6 & $3.5(3.1-4.5)$ вС & \\
\hline \multirow[t]{4}{*}{ Coliforms } & Rinsing & 2.7 & 1.5 & 4.2 & $2.6(2.2-3.1)$ в & $\mathrm{H}=35.7$ \\
\hline & Tissue excision & 3.1 & 2.0 & 4.5 & $3.0(2.7-3.6) \mathrm{A}$ & $P=0.00$ \\
\hline & Skin excision & 2.6 & 1.0 & 3.9 & $2.6(2.1-3.0)$ вС & \\
\hline & Skin swab & 2.4 & 1.0 & 4.0 & $2.3(2.0-2.8) \mathrm{C}$ & \\
\hline \multirow[t]{4}{*}{ E. coli } & Rinsing & 2.3 & 1.0 & 3.8 & $2.3(1.9-2.7)$ в & $H=26.6$ \\
\hline & Tissue excision & 2.7 & 2.0 & 3.8 & $2.6(2.3-3.1) \mathrm{A}$ & $P=0.00$ \\
\hline & Skin excision & 2.2 & 1.0 & 3.4 & $2.2(1.7-2.6)$ вС & \\
\hline & Skin swab & 2.0 & 1.0 & 3.7 & $2.0(1.6-2.3) \mathrm{C}$ & \\
\hline
\end{tabular}

${ }^{a}$ Values are in $\log \mathrm{CFU}$ per gram (tissue excision) or milliliter (rinsing, skin excision, and skin swab). $\mathrm{Q}_{1}$, lower quartile; $\mathrm{Q}_{3}$, upper quartile; Min, minimum; Max, maximum. For each group, median $\left(\mathrm{Q}_{1}\right.$ to $\left.\mathrm{Q}_{3}\right)$ values followed by different letters indicate significant differences by Mann-Whitney $\mathrm{U}$ test $(P<0.05)$.

${ }^{b} \mathrm{H}$, Kruskall-Wallis test value; $P$, level of significance (for each hygiene indicator microorganism group).

These results might be due to the ability of certain microorganisms to associate with carcass tissues, requiring the use of destructive methods to ensure adequate enumeration $(3,12)$. However, some studies have concluded that rinsing is the most efficient technique for sampling microorganisms present at low levels, such as E. coli (11, 24). Another factor that may compromise the efficiency of microorganism enumeration from a sample is the homogenization step. Ideally, this step should be standardized and performed using equipment suitable for the purpose. However, homogenization equipment is impractical for some samples and sampling protocols (e.g., rinsing) and requires direct sample manipulation by analysts, which could affect the recovery of some microbial groups (21). The similar efficiencies of tissue excision and rinsing for the enumeration of aerobic mesophiles and Enterobacteriaceae (Table 1) indicate the viability of using the nondestructive rinsing method for the recovery of these groups of microorganisms from poultry carcasses (3).

Skin swabbing and skin excision were equally effective for the enumeration of all groups of examined microorganisms (Table 1). However, these procedures were significantly different for both rinsing and tissue excision. Despite being widely used in scientific studies and official protocols, sampling methods that test only the surface contamination of carcasses have some limitations $(6,19,25)$. The relative effectiveness of superficial swabbing at removing attached microorganisms depends on the nature of the material used for sampling, and the use of more abrasive swabbing materials is regarded as the best option (9). Other studies suggest that swabbing produces inconsistent results, likely caused by the presence of antimicrobial residues on sampling sponges or even differences between homogenates $(5,7,16)$.
In order to allow direct comparisons between the evaluated sampling procedures, the data were correlated (Table 2). This analysis was conducted to verify the significance levels of the possible comparisons between sampling techniques, enabling adequate analysis of microbiological data obtained by distinct procedures. In most comparisons, the observed correlations were significant (with the exception of $E$. coli enumeration by tissue and skin excision sampling). Despite the large number of studies in the literature that compare different sampling protocols for animal carcasses $(4,10,11,17)$, the establishment of such correlations is often hampered by the large number of variables that influence results obtained by different methods $(1,3,15)$. Hutchison et al. (14) did not find a linear relationship between microbiological counts of animal carcasses sampled by skin swabbing and tissue excision, and they observed a nonuniform distribution of microorganisms in the analyzed carcasses (bovine, ovine, and swine). Thus, the correlations presented here should be an important reference for the food industry when choosing the optimal protocol to be adopted for quality control and security. Furthermore, the established correlations allow the selection of an adequate sampling technique, considering issues of practicality, economic feasibility, or even professional training of analysts.

The results reported herein demonstrate that among the various microbiological sampling methods for chicken carcasses, tissue excision showed a better performance in recovering hygiene indicator microorganisms. However, the observed differences are considered minor, and despite being significant in specific comparisons $(P<0.05)$, the 0.5 to 1.0 log range between the counts indicates similarities. This information should provide an important reference for government agencies 
TABLE 2. Statistical parameters for Spearman correlation between counts of hygiene indicator microorganisms from fresh chicken carcasses, obtained by distinct sampling procedures

\begin{tabular}{|c|c|c|c|c|c|}
\hline $\begin{array}{l}\text { Hygiene indicator } \\
\text { microorganism group }\end{array}$ & Sampling procedure comparison $(x: y)$ & Spearman index & $\begin{array}{c}\text { Determination } \\
\text { coefficient }\end{array}$ & $P^{a}$ & Curve equation \\
\hline \multirow[t]{6}{*}{ Mesophilic aerobes } & Skin swab:skin excision & 0.88 & 0.78 & $<0.01$ & $y=0.8 x+1.2$ \\
\hline & Rinsing:tissue excision & 0.77 & 0.59 & $<0.01$ & $y=0.8 x+1.2$ \\
\hline & Skin swab:rinsing & 0.87 & 0.75 & $<0.01$ & $y=0.8 x+1.3$ \\
\hline & Skin swab:tissue excision & 0.78 & 0.62 & $<0.01$ & $y=0.7 x+1.9$ \\
\hline & Skin excision:rinsing & 0.88 & 0.77 & $<0.01$ & $y=1.0 x+0.4$ \\
\hline & Skin excision:tissue excision & 0.75 & 0.56 & $<0.01$ & $y=0.8 x+1.5$ \\
\hline \multirow[t]{6}{*}{ Enterobacteriaceae } & Skin swab:skin excision & 0.77 & 0.60 & $<0.01$ & $y=0.6 x+1.6$ \\
\hline & Rinsing:tissue excision & 0.78 & 0.60 & $<0.01$ & $y=0.9 x+0.8$ \\
\hline & Skin swab:rinsing & 0.73 & 0.54 & $<0.01$ & $y=0.6 x+1.7$ \\
\hline & Skin swab:tissue excision & 0.71 & 0.50 & $<0.01$ & $y=0.7 x+1.7$ \\
\hline & Skin excision:rinsing & 0.73 & 0.54 & $<0.01$ & $y=0.9 x+0.6$ \\
\hline & Skin excision:tissue excision & 0.66 & 0.44 & $<0.01$ & $y=0.8 x+1.1$ \\
\hline \multirow[t]{6}{*}{ Coliforms } & Skin swab:skin excision & 0.75 & 0.56 & $<0.01$ & $y=0.7 x+1.0$ \\
\hline & Rinsing:tissue excision & 0.61 & 0.37 & $<0.01$ & $y=0.6 x+1.5$ \\
\hline & Skin swab:rinsing & 0.76 & 0.58 & $<0.01$ & $y=0.7 x+0.9$ \\
\hline & Skin swab:tissue excision & 0.55 & 0.31 & $<0.01$ & $y=0.6 x+1.7$ \\
\hline & Skin excision:rinsing & 0.74 & 0.55 & $<0.01$ & $y=0.8 x+0.6$ \\
\hline & Skin excision:tissue excision & 0.48 & 0.23 & $<0.01$ & $y=0.5 x+1.8$ \\
\hline \multirow[t]{6}{*}{ Escherichia coli } & Skin swab:skin excision & 0.65 & 0.42 & $<0.01$ & $y=0.7 x+0.9$ \\
\hline & Rinsing:tissue excision & 0.49 & 0.24 & $<0.01$ & $y=0.4 x+1.6$ \\
\hline & Skin swab:rinsing & 0.62 & 0.39 & $<0.01$ & $y=0.7 x+1.0$ \\
\hline & Skin swab:tissue excision & 0.39 & 0.16 & 0.02 & $y=0.5 x+1.7$ \\
\hline & Skin excision:rinsing & 0.72 & 0.53 & $<0.01$ & $y=0.6 x+0.9$ \\
\hline & Skin excision:tissue excision & 0.19 & 0.04 & 0.247 & $y=0.2 x+2.2$ \\
\hline
\end{tabular}

${ }^{a} P$, level of significance.

and the food industry in establishing appropriate protocols for sample collection and allowing for direct comparison of results obtained from different sampling procedures.

\section{ACKNOWLEDGMENTS}

L. A. Nero is supported by CNPq (303834/2009-9) and FAPEMIG (CVZ-PPM-00093-09). P. S. A. Pinto is supported by CNPq (303918/ 2009-8) and FAPEMIG (CVZ-PPM-00412-10). M. V. C. Cossi and M. V. Almeida are supported by CNPq (master scholarship), and M. R. Dias is supported by FAPEMIG (Scientific scholarship).

\section{REFERENCES}

1. Bolton, D. J. 2003. The EC decision of the 8th June 2001 (EC/471/ 2001): excision versus swabbing. Food Control 14:207-209.

2. Brasil-Agência Nacional de Vigilância Sanitária, Ministério da Saúde. 2001. RDC 12 -regulamento técnico sobre padrões microbiológicos para alimentos. Agência Nacional de Vigilância Sanitária, Brasília, Brazil.

3. Capita, R., M. Prieto, and C. Alonso-Calleja. 2004. Sampling methods for microbiological analysis of red meat and poultry carcasses. J. Food Prot. 67:1303-1308.

4. Cox, N. A., L. J. Richardson, J. A. Cason, R. J. Buhr, V. Vizzier-Thaxton, D. P. Smith, P. J. Fedorka-Cray, C. P. Romanenghi, L. V. B. Pereira, and M. P. Doyle. 2010. Comparison of neck skin excision and whole carcasses rinse sampling methods for microbiological evaluation of broiler carcasses before and after immersion chilling. J. Food Prot. 73:976-980.

5. Daley, E. F., F. Pagotto, and J. M. Farber. 1995. The inhibitory properties of various sponges on Listeria spp. Lett. Appl. Microbiol. 20:195-198.

6. European Commission. 2001. Commission decision of 8 June 2001 laying down rules for the regular checks in the general hygiene carried out by the operators in establishments according to Directive 64/433/EEC on health conditions for the production and marketing of fresh meat and Directive 71/118/ECC on health problems affecting the production and placing on the market of fresh poultry meat, p. 4853. Commission of the European Communities 2001/471/EC.

7. Gants, R. 1997. Biocide free \& sterile-precautions for sponge sampling. Meat Poult. 43:44-50.

8. Ghafir, Y., B. China, K. Dierick, L. De Zutter, and G. Daube. 2008. Hygiene indicator microorganisms for selected pathogens on beef, pork, and poultry meats in Belgium. J. Food Prot. 71:35-45.

9. Gill, C. O., A. Badoni, and J. C. McGinnis. 2001. Microbiological sampling of meat cuts and manufacturing beef by excision or swabbing. J. Food Prot. 64:325-334.

10. Gill, C. O., and M. Badoni. 2005. Recovery of bacteria from poultry carcasses by rinsing, swabbing or excision of skin. Food Microbiol. 22:101-107.

11. Gill, C. O., M. Badoni, L. F. Moza, S. Barbut, and M. W. Griffith. 2005. Microbiological sampling of poultry carcass portions by excision, rinsing, or swabbing. J. Food Prot. 68:2718-2720.

12. Gill, C. O., and T. Jones. 2000. Microbiological sampling of carcasses by excision or swabbing. J. Food Prot. 63:167-173.

13. Gill, C. O., L. F. Moza, A. Badoni, and S. Barbut. 2006. The effects on the microbiological condition of product of carcass dressing, cooling, and portioning processes at a poultry packing plant. Int. J. Food Microbiol. 110:187-193.

14. Hutchison, M. L., L. D. Walters, S. M. Avery, C. Reid, D. Wilson, M. Howell, A. M. Johnston, and S. Buncic. 2005. A comparison of wet-dry swabbing and excision sampling methods for microbiological testing of bovine, porcine, and ovine carcasses at red meat slaughterhouses. J. Food Prot. 68:2155-2162.

15. Hutchison, M. L., L. D. Walters, G. C. Mead, M. Howell, and V. N. Allen. 2006. An assessment of sampling methods and microbiological hygiene indicators for process verification in poultry slaughterhouses. J. Food Prot. 69:145-153.

16. Llabres, C. M., and B. E. Rose. 1989. Antibacterial properties of retail sponges. J. Food Prot. 52:49-50.

17. Miraglia, D., D. Ranucci, V. D'Ovidio, R. Branciari, and M. Severini. 2005. Comparison between carcass microbial load recovered by 
swabbing surfaces of different size and using the reference excision method. Vet. Res. Commun. 29:339-341.

18. Palumbo, S. A., P. Klein, J. Capra, S. Eblen, and A. J. Miller. 1999. Comparison of excision and swabbing sampling methods to determine the microbiological quality of swine carcass surfaces. Food Microbiol. 16:459-464.

19. Pearce, R. A., and D. J. Bolton. 2005. Excision vs sponge swabbing-a comparison of methods for the microbiological sampling of beef, pork and lamb carcasses. J. Appl. Microbiol. 98:896-900.

20. Rodrigues, A. C. A., P. S. A. Pinto, M. C. D.Vanetti, P. D. Bevilacqua, M. S. Pinto, and L. A. Nero. 2008. Análise e monitoramento de pontos críticos no abate de frangos utilizando indicadores microbiológicos. Cien. Rural 38:1948-1953.

21. Russell, S. M., N. A. Cox, and J. S. Bailey. 1997. Sampling poultry carcasses and parts to determine bacterial levels. J. Appl. Poult. Res. 6:234-237.
22. Snijders, J. M. A., M. H. W. Janssen, G. E. Gerats, and G. P. Cortiaensen. 1984. A comparative study of sampling techniques for monitoring carcass contamination. Int. J. Food Microbiol. 1:229-236.

23. U.S. Department of Agriculture-Food Safety and Inspection Service. 2008. Microbiology laboratory guidebook, section 4.04. Isolation and identification of Salmonella from meat, poultry, and egg products. U.S. Department of Agriculture-Food Safety and Inspection Service, Washington, DC. Available at: http://www.fsis. usda.gov/PDF/MLG_4_04.pdf. Accessed 17 May 2011.

24. Werlein, H. D. 2001. Comparison of destructively and rinsing gained samples to determine TVC of pig carcasses by bioluminescence. Meat Sci. 59:165-168.

25. Zweifel, C., D. Baltzer, and R. Stephan. 2005. Microbiological contamination of cattle and pig carcasses at five abattoirs: determination by swab sampling in accordance with EU Decision 2001/471/EC. Meat Sci. 69:559-566. 